\title{
Natural Variability of Shear Strength in a Granite Residual Soil from Porto
}

\author{
Luís Pinheiro Branco • António Topa Gomes • \\ António Silva Cardoso · Carla Santos Pereira
}

Received: 18 November 2013/ Accepted: 26 April 2014/Published online: 9 May 2014

(C) The Author(s) 2014. This article is published with open access at Springerlink.com

\begin{abstract}
The renewal imposed by the Eurocodes regarding the methodologies of safety evaluation requires a statistical analysis of the variability of ground geotechnical parameters. However, the studies published in the reviewed literature do not cover the typical materials from the northeast region of Portugal-residual soils from granite- to which a strong heterogeneity is associated. Hence, a statistical characterization of the natural variability of a granite residual soil from Porto has been made through a significant amount of experimental tests, focusing on its geomechanical properties. In order to provide a database for probabilistic analysis of problems involving this type of soils, an appropriate statistical law has been used to model its variability, which has been
\end{abstract}

L. Pinheiro Branco $(\bowtie)$

AdFGeo - Consultores de Geotecnia, Rua Fernão Lopes, 157 - $4^{\circ}$ Esq, Porto 4150-318, Portugal

e-mail: lcpdbranco@gmail.com

A. Topa Gomes · A. Silva Cardoso

Department of Civil Engineering, Faculty of Engineering, University of Porto, Rua Dr. Roberto Frias,

Porto 4200-465, Portugal

C. Santos Pereira

Portucalense University Infante D. Henrique, Rua Dr. António Bernardino de Almeida, 541, Porto 4200-072, Portugal quantified by means of coefficients of variation and scales of fluctuation.

Keywords Residual soils - Shear strength · Natural variability $\cdot$ Coefficient of variation . Scale of fluctuation

\section{Introduction}

The concept of safety and its evaluation has experienced a remarkable evolution over the last few years. However, the determination of a global factor of safety is still widely used in the design of geotechnical structures, which creates additional difficulties in understanding the influence in design resulting from the uncertainties in the different parameters. Therefore, following the renewal imposed by Eurocodes, deterministic methodologies will tendentiously be replaced by more rational approaches, such as semiprobabilistic methods-for example, the partial coefficients method-and probabilistic methods based on the reliability theory.

An extensive characterization of the variability of geotechnical parameters must be carried out to enable the transition to be fulfilled. This characterization should be as objective as possible, avoiding ambiguities provided by qualitative descriptions, as suggested by Kulhawy and Phoon (1999) who recommend a statistical analysis including the coefficient of 


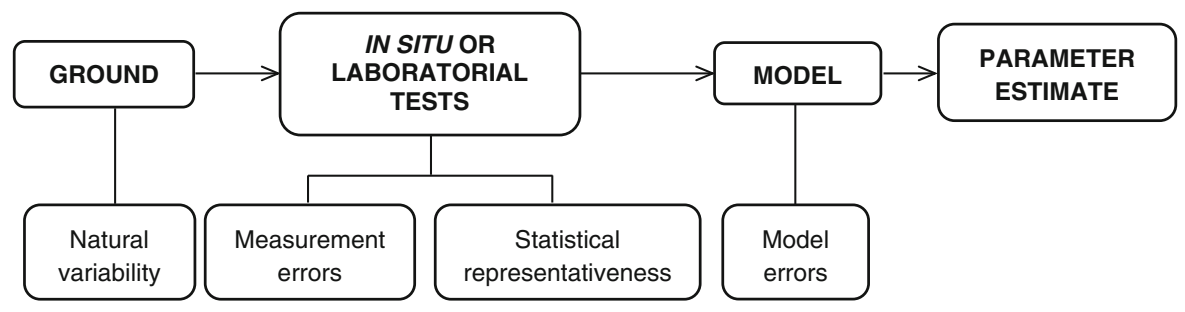

Fig. 1 Sources of uncertainty in geotechnics (Kulhawy and Phoon 1999, adapted)

variation and the scale of fluctuation. Although the literature provides benchmarks for sands and clays, quantitative studies devoted to the variability of residual soils are scarce and their singular characteristics require specific treatment.

Accordingly, Pinheiro Branco (2011) performed a significant amount of direct shear tests in order to characterize the natural variability of a granite residual soil from Porto, namely its shear strength but also some physical properties. The test results were subjected to a statistical treatment focused on the coefficient of variation and the scale of fluctuation and the main conclusions are discussed in this paper.

\section{Residual Soils Variability}

\subsection{Uncertainties in Geotechnics}

The main difference between geotechnics and other fields of civil engineering has to do with the fact that geotechnical problems involve natural materials, namely soils and rocks, whose properties depend on natural processes which humans cannot control. Consequently, site geotechnical characterization involves inferences to be carried out from limited data and dealing with different sources of uncertainty (see Fig. 1).

As shown in Fig. 1, there are three main sources of uncertainty when estimating ground parametersnatural variability, measurement errors and model errors. As this paper deals with residual soils, which present a strong heterogeneity, natural variability takes additional importance and is going to be the principal topic addressed.

\subsection{The Particular Case of Residual Soils}

Residual soils derive from weathering of underlying parent rocks, having a wide particle size distribution and a bonded structure, where coarse grains (in the case of granite residual soils, usually minerals of quartz) are bonded by fragile clayey bridges (Viana da Fonseca et al. 1997).

In contrast to sedimentary deposits, which generally present horizontal stratification, residual soils profiles are particularly random. Indeed, there might be sites in which there is a mass of residual soil surrounded by intact rock and other sites where boulders can be found within a thick layer of residual soil (Viana da Fonseca et al. 2010).

So, as residual soils genesis depends on weathering factors which are not constant in place, a variability analysis should also take into account its spatial components, both vertical and horizontal.

\subsection{Natural Variability Quantification}

\subsubsection{Coefficient of Variation and Scale of Fluctuation}

Kulhawy and Phoon (1999) suggest the use of two quantitative attributes to analyze ground natural variability, namely the coefficient of variation and the scale of fluctuation.

The coefficient of variation is a normalized measure of data dispersion which, for a sample of size $n\left(y_{1}\right.$, $\left.y_{2}, \ldots y_{n}\right)$, can be estimated for an arbitrary variable $Y$ using eq. (1) (Curto and Pinto 2009).

$\widehat{c v}_{y}=\frac{\sqrt{\frac{\sum_{i=1}^{n}\left(y_{i}-\widehat{\mu_{y}}\right)^{2}}{n-1}}}{\widehat{\mu_{y}}}$

where $\widehat{\mu_{y}}$ is the sample estimate of the mean (that is, the arithmetic mean of $n$ data values which constitute the sample of $Y$ ).

Regarding the scale of fluctuation, consider, by way of example, the unsupported slope of residual soil 


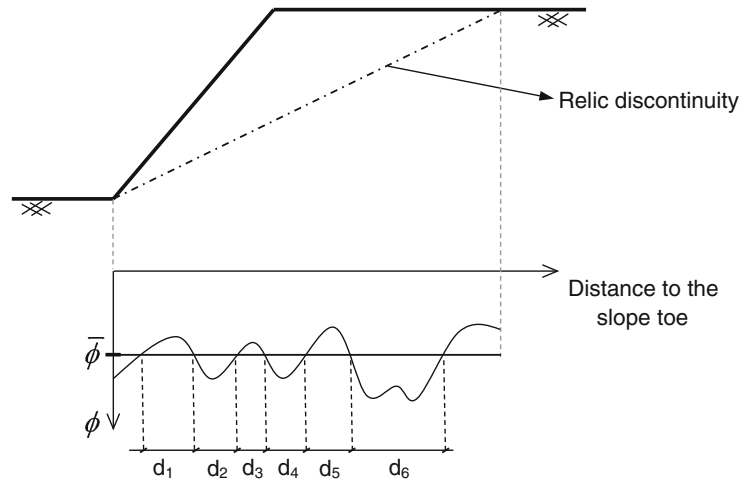

Fig. 2 Cross section of a slope in residual soil and friction angle along a relic discontinuity

illustrated in Fig. 2 which is on the verge of sliding along a relic discontinuity of its parent rock. Figure 2 also presents a graphical representation of the variation of the friction angle, $\varnothing$, along the weak strength plane, as well as its mean value.

As shown in Fig. 2, the friction angle along the sliding surface is not constant. So, in order to take into account spatial fluctuations around the mean value, it is opportune to introduce the concept of scale of fluctuation, $\delta$. The scale of fluctuation of a given property measures the distance over which the ground properties present values of the same order of magnitude, at least with respect to the tendency defined by the mean value, indicating the existence of some correlation between the properties of adjacent points (Vanmarcke 1977). Its value can be determined roughly using eq. (2) (Kulhawy and Phoon 1999).

$\delta \simeq 0.8 \times \bar{d}$

in which $\bar{d}$ is the average distance between intersections of the curve representing the real value of a given property and its average curve (see Fig. 2).

In practice, the scale of fluctuation is crucial to understand the behavior of potentially unstable masses of soil. Indeed, soils behave as highly hyperstatic structures; therefore, if a particular loading leads to failure of the most fragile areas, there can be a redistribution of shear stresses to adjacent areas with greater strength. However, this load redistribution can only take place before failure if the surface on which shear strength is mobilized is large enough to ensure that the overall soil behavior is governed by it average resistance (Silva Cardoso and Matos Fernandes 2001). That is, the scale of fluctuation represents a point of reference used to determine if the failure surface is
Table 1 Typical coefficients of variation in soils

\begin{tabular}{|c|c|c|c|}
\hline Property & Soil Type & $\begin{array}{l}c v \\
(\%)\end{array}$ & Reference \\
\hline Unit weigth & $\begin{array}{l}\text { Sands and } \\
\text { clays }\end{array}$ & $3-7$ & Duncan (2000) \\
\hline \multirow{3}{*}{$\begin{array}{l}\text { Effective } \\
\text { friction } \\
\text { angle }\end{array}$} & Sands & $3-12$ & Duncan (2000) \\
\hline & & $5-15$ & $\begin{array}{l}\text { Baecher and Christian } \\
\text { (2003) }\end{array}$ \\
\hline & Clays & $12-56$ & $\begin{array}{l}\text { Baecher and Christian } \\
\text { (2003) }\end{array}$ \\
\hline \multirow[t]{2}{*}{$\begin{array}{l}\text { Effective } \\
\text { cohesion }\end{array}$} & $\begin{array}{l}\text { Sands and } \\
\text { clays }\end{array}$ & $10-70$ & $\begin{array}{l}\text { Shahin and Cheung } \\
\text { (2011) }\end{array}$ \\
\hline & & $20-40$ & Forrest and Orr (2010) \\
\hline Voids ratio & $\begin{array}{l}\text { Sands and } \\
\text { clays }\end{array}$ & $7-42$ & $\begin{array}{l}\text { Baecher and Christian } \\
\text { (2003, adapted) }\end{array}$ \\
\hline
\end{tabular}

large enough so that shear stresses can really be redistributed. In order to take that internal redistribution capacity into account in calculations, Silva Cardoso and Matos Fernandes (2001) suggest the use of a corrected coefficient of variation, $c v_{\text {real }}$, defined as:

$c v_{\text {real }}=c v \times \prod_{i=1}^{n}\left(\frac{\delta_{i}}{L_{i}}\right)^{1 / 2}$

where the dimensions of a potentially unstable mass of soil are defined by $L_{i}$, while $\delta_{i}$ are the corresponding scales of fluctuation; note that $i$ refers to a particular spatial direction out of the $n$ along which the fluctuations of the property in analysis are considered.

\subsubsection{Typical Statistical Parameters and Scales of Fluctuation in Soils}

Table 1 summarizes common coefficients of variation related to some physical and mechanical properties of sandy and clayey soils, constituting the main references with regard to the characterization of the natural variability of soils.

Concerning the spatial component of variability, the parameters characterized in terms of scale of fluctuation are mainly the ones that can be evaluated from in situ tests that provide a continuous record of ground properties. The values indicated for undrained shear strength obtained from vane-tests and for CPT tip resistance are presented in Table 2, resulting that horizontal scales of fluctuation tend to be one order of magnitude greater than the vertical ones. 
Table 2 Typical scales of fluctuation in soils (Kulhawy and Phoon 1999, adapted)

\begin{tabular}{lllc}
\hline Property & Soil type & Direction & $\delta(\mathrm{m})$ \\
\hline Undrained shear & Clays & Vertical & $0.8-6.2$ \\
strength & & Horizontal & $46.0-60.0$ \\
Tip Resistance & Sands and & Vertical & $0.1-2.2$ \\
(CPT) & clays & Horizontal & $3.0-80.0$ \\
\hline
\end{tabular}

The variability of most geotechnical parameters can be modeled with normal distributions. However, when data values are low, spread out and cannot be negative, as it happens with cohesion, using normal distributions may not be appropriate. In fact, Forrest and Orr (2010) suggest instead the use of a lognormal distribution to model the variability of cohesion, since it only assumes non-negative values and gives a greater weight to lower values.

\section{Natural Variability of a Granite Residual Soil from Porto}

Samples of residual soil were collected in Porto, Portugal (see Fig. 3)—geographical coordinates in the
UTM Datum WGS84: $41.17330^{\circ}$ (latitude) and $-8.60195^{\circ}$ (longitude).

Geologically, it is a residual soil from granite, with a W5 weathering state, presenting a stained aspect, where it is possible to differentiate a whitish stain with completely weathered feldspars from a yellowish stain, which has more sand and presents oxidized biotites (see Fig. 4). It was found that this heterogeneity was not only random in plan view, but also in depth (see Fig. 4b).

The natural variability of shear strength in the study area of approximately $1.15 \times 1.15 \mathrm{~m}^{2}$, presented in Fig. 4, was characterized through 40 standard direct shear tests. Samples were grouped together in 10 sets of four samples each, as schematized in Fig. 5, for which peak and constant volume shear strength were evaluated in drained conditions by tests conducted under normal stresses of 25, 50, 75 and $100 \mathrm{kPa}$.

All procedures related to direct shear tests, including in situ sampling, preservation, transportation and preparation of samples in the laboratory, were carried out according to a standard test method-ASTM D3080-04. Succinctly, and highlighting some important aspects, the procedure was the following:

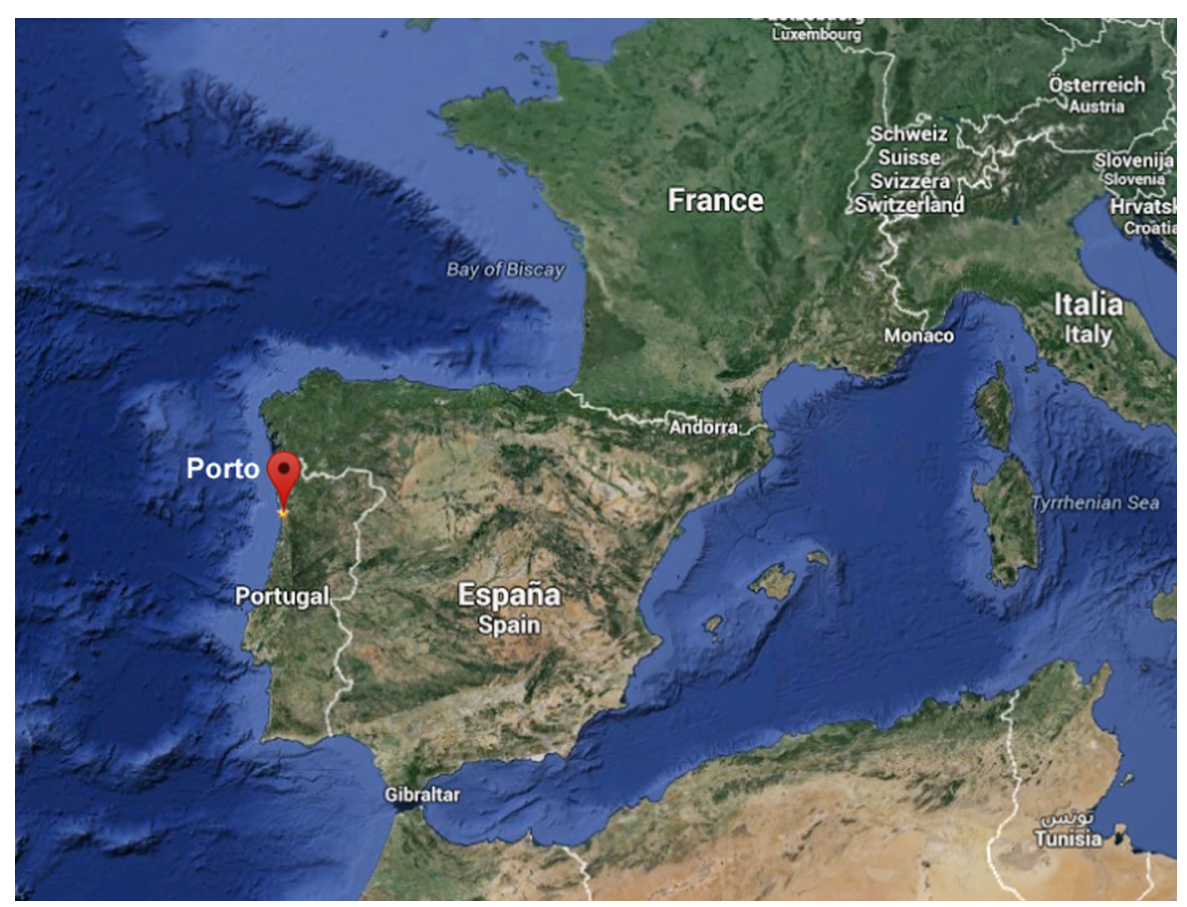

Fig. 3 Map showing the geographical location of Porto (Google Maps 2014) 
Fig. 4 Detail of study area after topsoil removing: (a) previous to sampling (b) evolution of the yellowish stain of oxidized biotites after sampling
Fig. 5 Study area scheme with the ten sets of samples

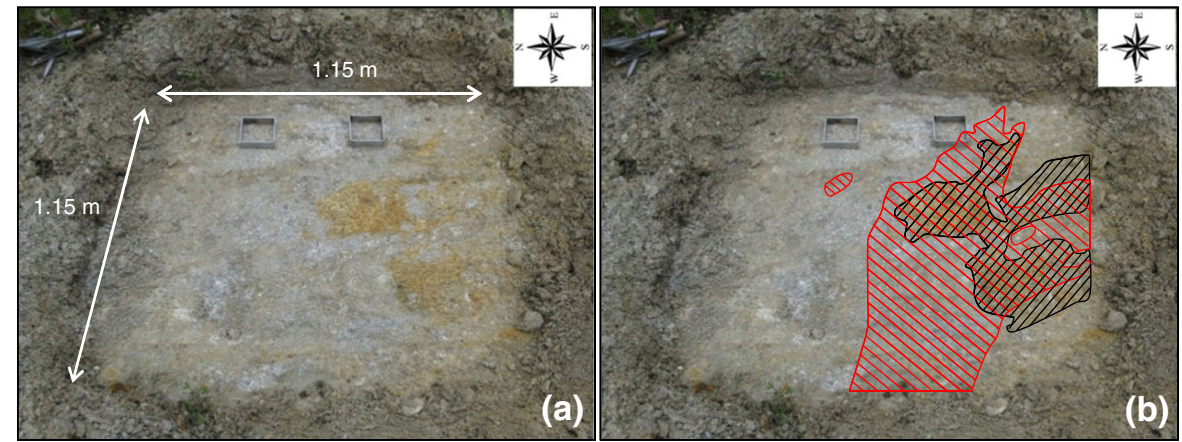

Legend:

$\theta$-yellowish stain of oxidized biotites $\theta$-yellowish stain of oxidized biotites after previous to sampling

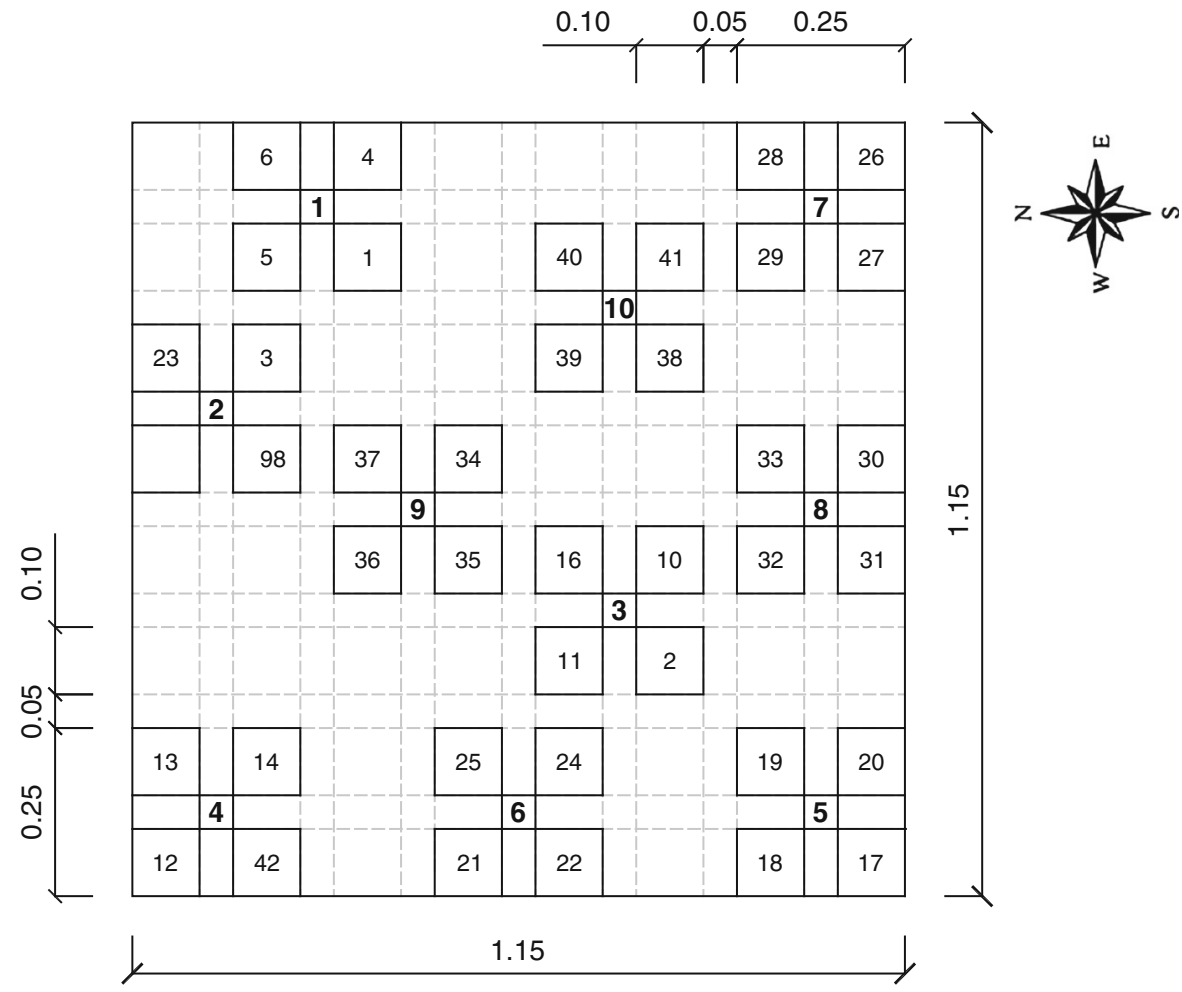

- undisturbed samples were collected thoroughly using cutters $\left(0.10 \times 0.10 \times 0.03 \mathrm{~m}^{3}\right)$ with the aid of a sharp knife to prevent disturbance to the structure of the natural soil (see Fig. 6);

- specimens were prepared in the laboratory for testing by trimming oversized samples very carefully to the inside dimensions of the shear box (see Fig. 7);

- after submerging specimens in water, shear tests were conducted at a uniform rate of displacement of $0.03 \mathrm{~mm} / \mathrm{min}$, which is assumed to have been slow enough to ensure shear testing under drained conditions.

As a final remark, note that although the standard direct shear box is not the most accurate laboratorial shear apparatus, it is important to underline that its use intends to quantify the natural variability of the material and not necessarily the exact value of the property. So, if all samples are subjected to the same experimental procedure and results are treated equally, 

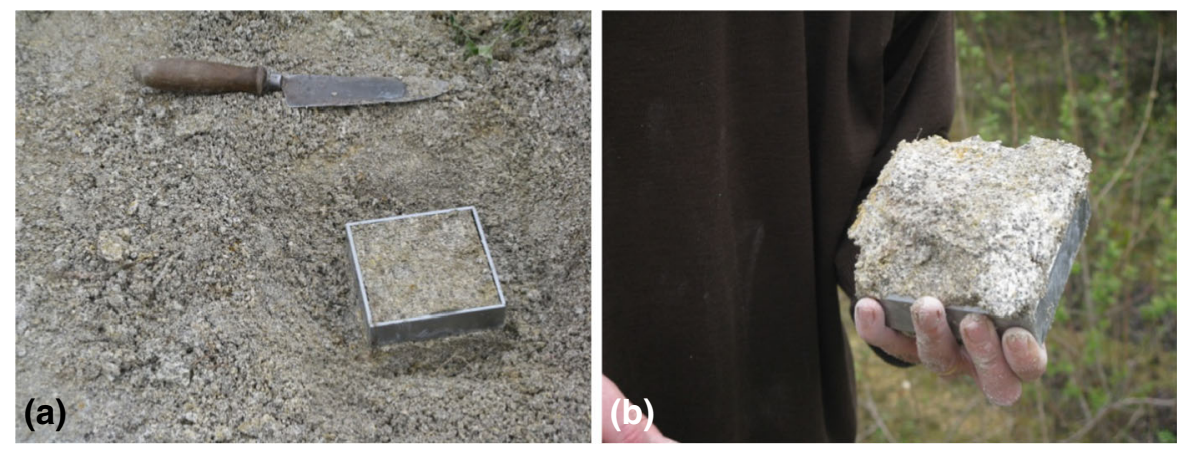

Fig. 6 Sampling procedure: (a) sampling in progress (b) collected sample
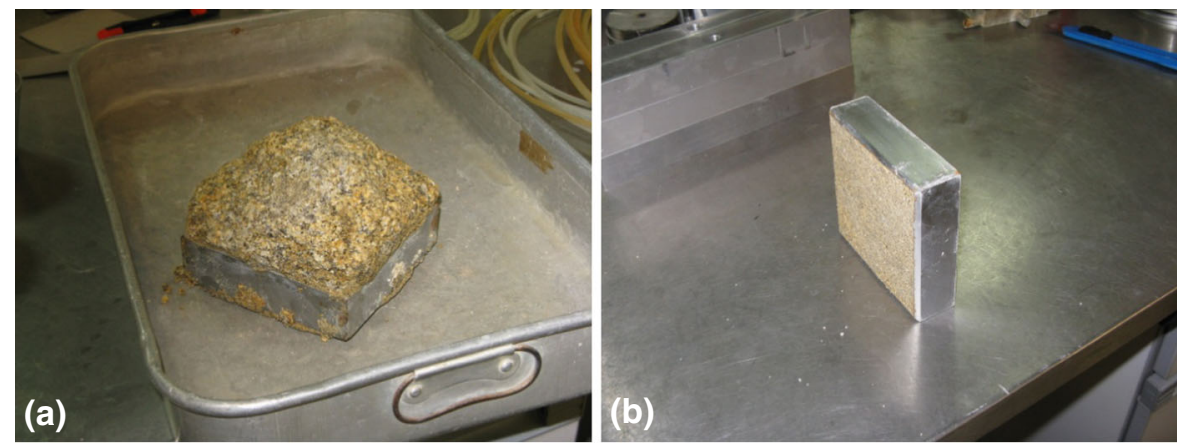

Fig. 7 Preparation of specimens for testing: (a) sample with protruded material (b) specimen after trimming

then the differences between the obtained parameters are mainly due to natural variability, since methodology errors are systematic.

\subsection{Natural Variability of Soil Skeleton}

During specimen preparation for direct shear tests, two properties which define its physical state in situ were determined-natural unit weight and moisture content. Nevertheless, the evaluation of the natural variability of a soil skeleton, particularly in residual soils, should be carried out using parameters not dependent on the water content, such as dry unit weight and voids ratio. These parameters were determined for each sample and subsequently analysed using statistical procedures (see Table 3, where saturated unit weight is also shown due to its importance in several geotechnical problems).

Note that the values for the coefficient of variation of the dry unit weight and the voids ratio are in accordance with the ranges presented in Table 1 for sands and clays. As sedimentary soils are typically more uniform, higher values could be expected in residual soils. However, it is important to acknowledge that unlike clays, where there is a strong correlation between water content and voids ratio, the skeleton of residual soils is significantly more compact and rigid; thus, in residual soils, voids ratio is not so dependent on water content.

In modeling the variables distribution, KolmogorovSmirnov Test has proved that normal distribution fits adequately to the set of 42 observations of each three physical properties in question. In fact, the $p$-value, that is, the probability of obtaining a test statistic at least as extreme as the one that has actually been observed under the hypothesis of assuming that variables are, in this case, normally distributed, is higher than the level of significance, $\alpha$, commonly adopted, $5 \%$ (Weber et al. 2006), as it is shown in Table 4.

\subsection{Natural Variability of Shear Strength}

The characterization of shear strength for the range of normal stresses chosen, 25-100 kPa, was carried out 
Table 3 Statistical parameters related to dry and saturated unit weight and voids ratio

\begin{tabular}{llllcc}
\hline Property & N. Samples & $\hat{\mu}$ & $\widehat{c v}(\%)$ & Minimum & Maximum \\
\hline Dry unit weight & 42 & $16.4 \mathrm{kN} / \mathrm{m}^{3}$ & 3.5 & $15.1 \mathrm{kN} / \mathrm{m}^{3}$ & $17.8 \mathrm{kN} / \mathrm{m}^{3}$ \\
Voids ratio & 42 & 0.58 & 9.6 & 0.45 & 0.72 \\
Saturated unit weight & 42 & $20.0 \mathrm{kN} / \mathrm{m}^{3}$ & 1.8 & $19.1 \mathrm{kN} / \mathrm{m}^{3}$ & $20.8 \mathrm{kN} / \mathrm{m}^{3}$ \\
\hline
\end{tabular}

Table 4 Appropriate statistical laws to model the variability of physical properties

\begin{tabular}{lllll}
\hline Property & Distribution & $\begin{array}{c}p \text {-value } \\
(\%)\end{array}$ & $\begin{array}{l}\alpha \\
(\%)\end{array}$ & $\begin{array}{l}\text { Kolmogorov- } \\
\text { Smirnov Test }\end{array}$ \\
\hline $\begin{array}{c}\text { Dry unit } \\
\text { weight } \\
\text { Voids ratio }\end{array}$ & Normal & 53 & 5 & $\begin{array}{c}\text { Hypothesis not } \\
\text { rejected }\end{array}$ \\
$\begin{array}{c}\text { Sormal } \\
\text { weight }\end{array}$ & 25 & 5 & $\begin{array}{c}\text { Hypothesis not } \\
\text { rejected }\end{array}$ \\
\hline
\end{tabular}

using sets of four adjacent samples (see Fig. 5), assuming the standardization of soil behavior within the area of each set, that is, considering the soil does not hide eventual heterogeneities. For each set, both peak and constant volume shear strength have been estimated by Mohr-Coulomb criterion. The maximum stress of $100 \mathrm{kPa}$ has been adopted since the maximum in situ stress was roughly of this order (see Fig. 8). In such conditions, it was guaranteed that the soil skeleton was not broken during the consolidation phase of the direct shear test.

All shear tests were carried under drained conditions to which correspond effective shear strengths; henceforth, to avoid repetitions, the word "effective" is going to be left out. In every single test, the peak and constant volume shear strength were recorded, as well as the normal stress under which the test was conducted. Afterwards, applying the Least-Squares Method to the points which represent the state of stress at failure, two Mohr-Coulomb envelopes were obtained for all sets of samples. In Table 5, relevant statistical data related to the experimental results is shown, namely the parameters defining the Mohr-Coulomb failure envelope for both peak and constant volume strength.

The coefficient of variation for peak friction angle of the granite residual soil from Porto is acceptable according to the benchmarks presented in literature for sandy soils (see Table 1). On the other hand, cohesion presents very random values, with a coefficient of

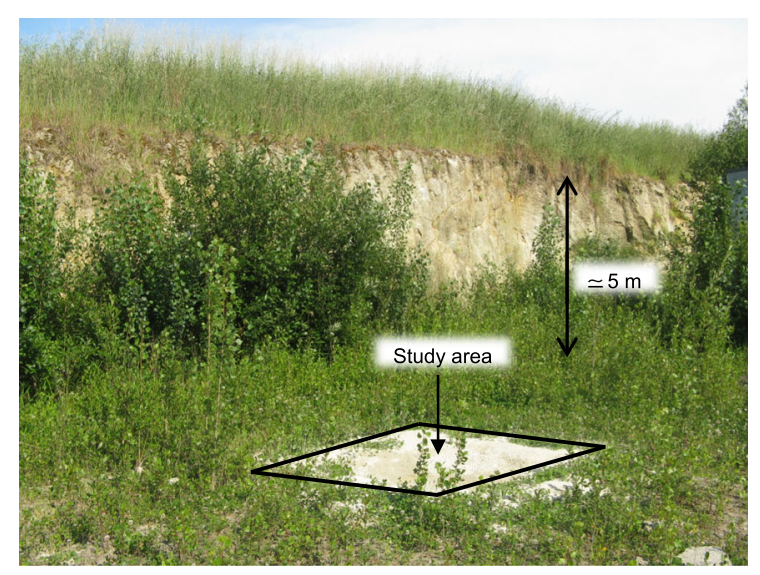

Fig. 8 Excavation slope and location of the study area

variation close to the upper bound indicated by Shahin and Cheung (2011) for sands and clays-70\%. Consequently, and given that the variability of constant volume shear strength is almost insignificant, it has been concluded that the variability of the fabric of residual soils is what contributes the most for the uncertainties related to their geomechanical characteristics. This variability results also from the nonlinearity of the Mohr-Coulomb failure criterion, particularly for low normal stresses. In any case, since Mohr-Coulomb failure criterion is so popular for practical purposes, it is important to take note of the high coefficients of variation associated with the use of this model, even having in mind that the values presented for cohesion and peak friction angle should only be considered valid for the range of tested normal stresses.

As to the statistical law that governs the distribution of both peak and constant volume friction angles, the hypothesis of normality has not been rejected by Komogorov-Smirnov Test, as it can be confirmed in Table 6.

However, the set of ten results obtained for cohesion make it difficult to find a statistical law fitting its statistical distribution (see Fig. 9). 
Table 5 Statistical parameters related to peak and constant volume strength

\begin{tabular}{lllccl}
\hline Property & N. Sets of Samples & $\hat{\mu}$ & $\widehat{c v}(\%)$ & Minimum & Maximum \\
\hline Peak friction angle & 10 & $40.3^{\circ}$ & 7.9 & $36.3^{\circ}$ & $45.6^{\circ}$ \\
Cohesion & 10 & $9.3 \mathrm{kPa}$ & 68.0 & $0.2 \mathrm{kPa}$ & $18.9 \mathrm{kPa}$ \\
Constant volume friction angle & 10 & $37.5^{\circ}$ & 3.4 & $35.3^{\circ}$ & $39.4^{\circ}$ \\
\hline
\end{tabular}

Table 6 Suitable statistical laws to model the variability of friction angles

\begin{tabular}{lllll}
\hline Property & Distribution & $\begin{array}{l}p \text {-value } \\
(\%)\end{array}$ & $\begin{array}{l}\alpha \\
(\%)\end{array}$ & $\begin{array}{l}\text { Kolmogorov- } \\
\text { Smirnov Test }\end{array}$ \\
\hline $\begin{array}{l}\text { Peak friction } \\
\text { angle }\end{array}$ & Normal & 93 & 5 & $\begin{array}{c}\text { Hypothesis } \\
\text { not rejected }\end{array}$ \\
$\begin{array}{c}\text { Constant } \\
\text { volume } \\
\text { friction angle }\end{array}$ & Normal & 88 & 5 & $\begin{array}{c}\text { Hypothesis } \\
\text { not rejected }\end{array}$ \\
\hline
\end{tabular}

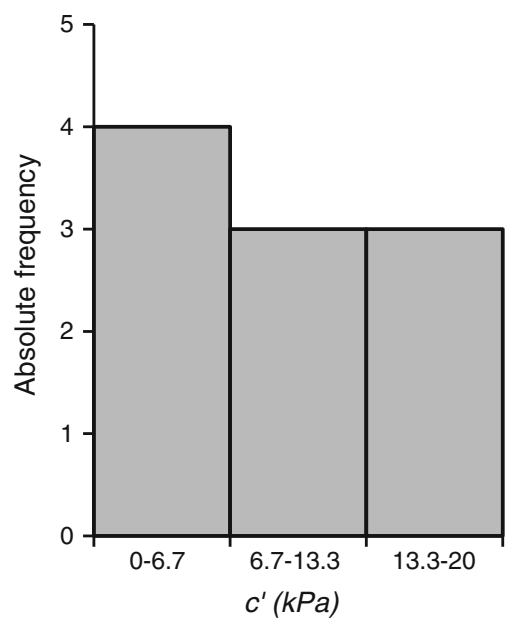

Fig. 9 Histogram of the cohesion of the ten sets of samples

Indeed, even the lognormal distribution suggested by Forrest and Orr (2010) does not fit the results distribution, since, among other reasons, it does not allow the cohesion to assume null values. In order to work around this problem, a hypothetical scenario where only four shear tests had been made to characterize this soil mass was considered. For this hypothetical case, and taking into account that there are 40 experimental results, 10 for each normal stress, it is possible to proceed to $10 \times 10 \times 10 \times 10=10000$ random groupings of four samples. The dispersion concerning this scenario is represented in Fig. 10.
The histogram represented in Fig. 10 shows a decreasing tendency of the probability of occurrence as the cohesion increases. Moreover, the class of values lower than $2.5 \mathrm{kPa}$ has the highest absolute frequency, including 916 null cohesions, approximately $10 \%$ of the values obtained by this procedure. This is a consequence of the physical impossibility of negative cohesions and thus, it seems more appropriate and cautious to consider an exponential distribution to model its variability.

\subsubsection{Scale of Fluctuation of Peak Strength}

When the shear strength is defined by Mohr-Coulomb failure criterion, the peak friction angle and the cohesion cannot be detached, because it depends on the combination of these two parameters. In fact, cohesion and peak friction angle are correlated and, in this particular soil, there is a strong negative correlation defined by a coefficient of correlation, $R$, of approximately -0.9 (see Fig. 11).

As a result, the comparison between the shear strength exhibited by each set of four samples should be made using another parameter, for example the secant friction angle suggested by Bolton (1986) for sands.

The secant friction angle can be interpreted as a normalization of shear strength, since it is defined as the angle associated with the ratio between the shear strength exhibited by a sample and the normal stress under which the test was carried out. Since shear tests were conducted under the four normal stresses considered for every set of samples, the arithmetic mean of the four secant peak friction angles is representative of the "average" peak shear strength of each sample for the tested range of normal stresses. The map of spatial variability of the secant peak friction angle is shown in Fig. 12.

As Fig. 12b shows, the mean value of the secant peak friction angle and subsequently the variability of the peak shear strength does not present a dispersion as noteworthy as the one related to the cohesion. Moreover, 


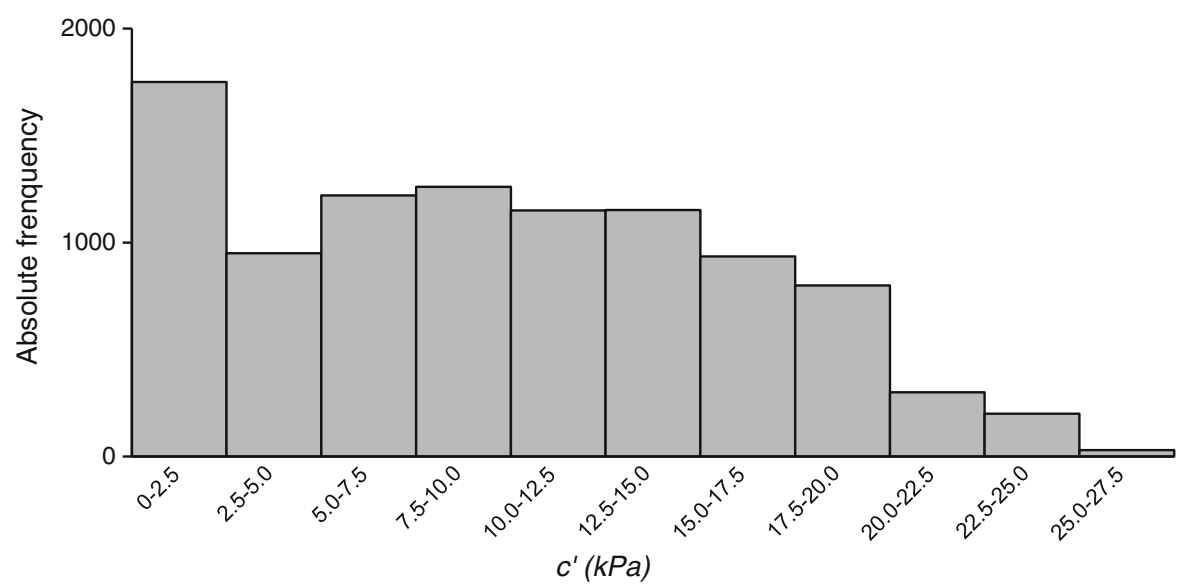

Fig. 10 Histogram of cohesion with random groupings of four samples

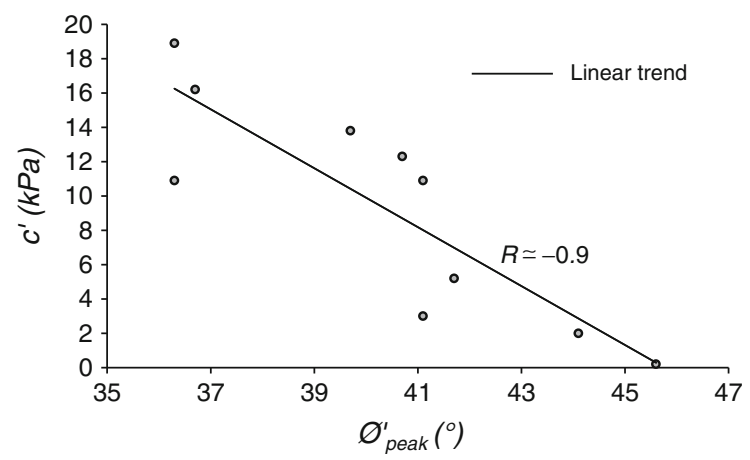

Fig. 11 Correlation between peak friction angle and cohesion

spatial fluctuations are both random and almost negligible.

So, in order to objectify the spatial component of the natural variability of the peak shear strength, the value of the horizontal scale of fluctuation related to the "average" secant peak friction angle has been determined by the following expedited method.

First, several polylines were defined by an almost random process of grouping sets of samples located within the area in analysis. Those polylines were defined by connecting the geometrical centres of some sets of four samples which characterize areas of $0.25 \times 0.25 \mathrm{~m}^{2}$. And so, the spatial fluctuations of the "average" peak shear strength within the area of $1.15 \times 1.15 \mathrm{~m}^{2}$ can somehow be perceived by analyzing the fluctuations of the "average" secant peak friction angle along those polylines.

Furthermore, the quantification of the horizontal scale of fluctuation of the "average" peak shear strength requires the definition of a representative value of the shear strength of the whole area in analysis. As, excluding heterogeneity, the shear strength exhibited by a soil at the same depth and thereafter under the same confining stress should be roughly constant, it seems reasonable to consider the arithmetic mean of the 10 "average" secant peak friction angles as an appropriate reference value for the purpose of estimating the scale of fluctuation.

Hence, considering three different combinations of sets of samples (7-10-9-3-5, 1-2-9-3-5 and 1-10-8-3-64 , identified in Fig. 12), the horizontal scale of fluctuation of the peak shear strength was estimated using eq. (2) $-0.37,0.29$ and $0.42 \mathrm{~m}$, respectively. As an example, Fig. 13 shows the fluctuations of the "average" secant peak friction angle for the combination of sets of samples resulting in a scale of fluctuation of $0.42 \mathrm{~m}$.

Cautiously, it can be said that an indicative value of the horizontal scale of fluctuation of the peak shear strength of the soil in analysis is $0.4 \mathrm{~m}$, which is notably lower than the ones referred to other geotechnical parameters that characterize the shear strength of both sandy and clayey soils (see Table 2).

\subsubsection{Scale of Fluctuation of Constant Volume Strength}

The same procedure has been applied to the "average" secant constant volume friction angle and the values obtained for the corresponding horizontal scale of fluctuation are $0.40,0.52$ and $0.33 \mathrm{~m}$, respectively, for the following sets of samples: 7-10-9-3-5, 1-2-9-3-5 


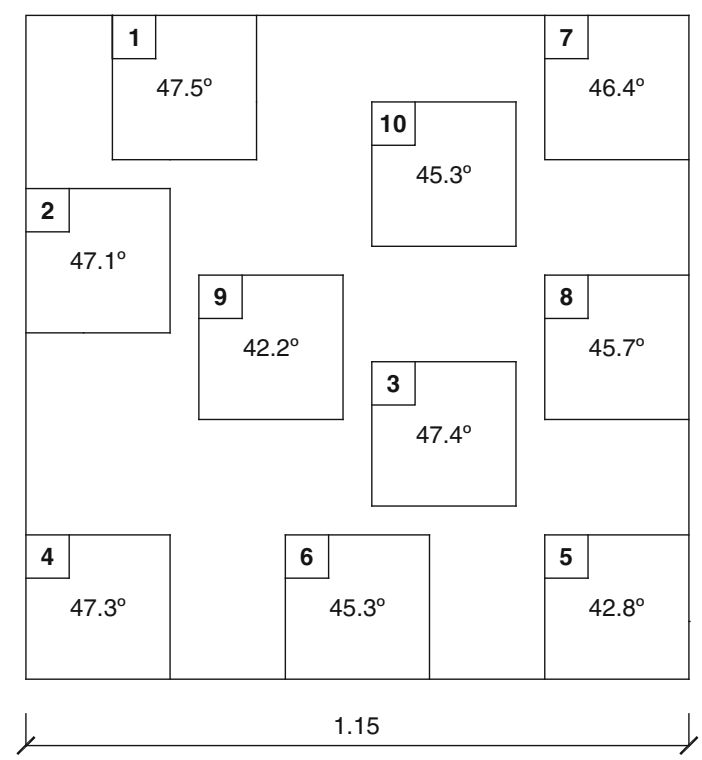

(a)

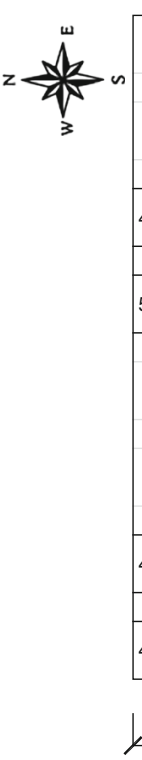

(b)

Fig. 12 Maps of spatial variability of the secant peak friction angle: (a) by set of samples (average strength) (b) by sample

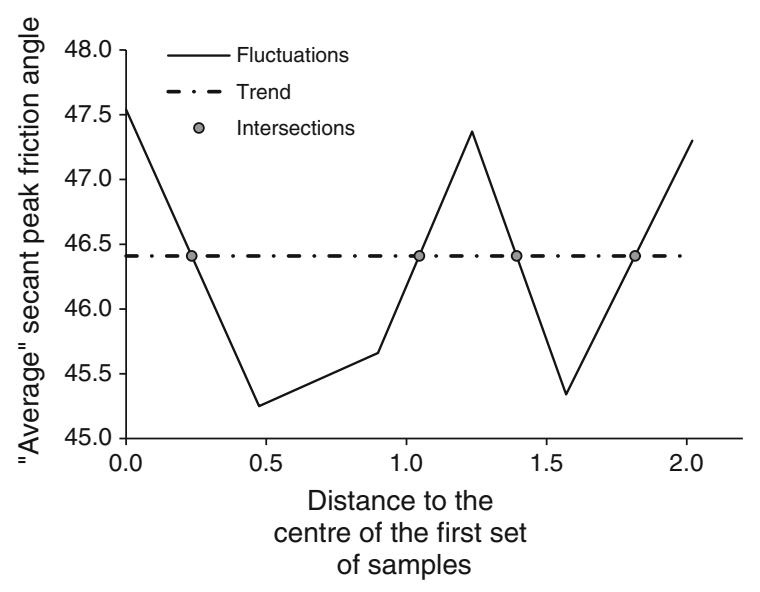

Fig. 13 Deviations from trend of the "average" secant peak friction angle along the following sets of samples: $1,10,8,3,6$ and 4

and 1-10-8-3-6-4. Hence, the horizontal scale of fluctuation of the constant volume shear strength can be taken as $0.5 \mathrm{~m}$.

\subsubsection{Influence of Scales of Fluctuation in Coefficients of Variation}

As a consequence, the coefficients of variation of both peak and constant volume shear strength parameters, that is, peak and constant volume friction angles and cohesion, should be reduced according to Eq. (3). That is, when analysing the stability of a mass of this particular residual soil along a given failure surface, the coefficients of variation to be considered should be the ones presented in Fig. 14 and Fig. 15, which depend on the length of the failure surface itself. Note that, to simplify this proposal, it is assumed that the vertical scale of fluctuation of the property in analysis is equal to the horizontal one, which seems to be an appropriate assumption for residual soils.

However, it should be noted that the determined scales of fluctuation cannot be higher than the dimensions of the area used to their determination. As this area is particularly small to be considered a representative sample of this highly heterogeneous granitic soil, the estimates presented for both scales of fluctuation do not obviously intend to settle definitive benchmarks for this type of soils. Its purpose is only to contribute for the development of the characterization of the spatial variability of residual soils in general by presenting the analysis of the results of shear tests run on 40 samples of this particular soil.

\subsubsection{Characteristic Values}

According to clause 2.4.5.2(2) of EN 1997-1:2004/ AC:2009, "the characteristic value of a geotechnical 


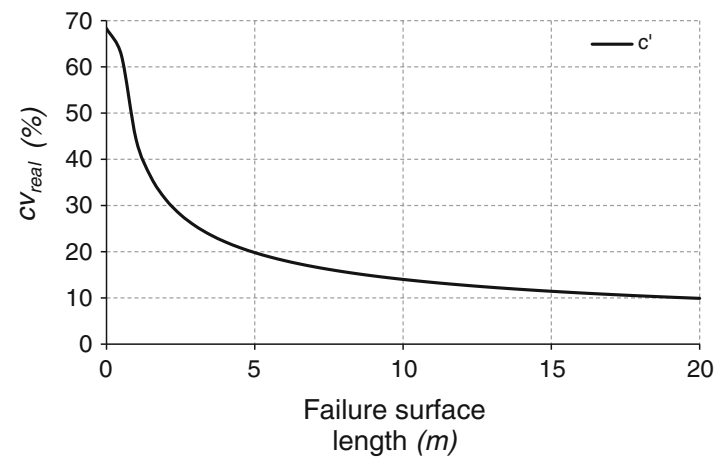

Fig. 14 Influence of the scale of fluctuation in the reduction of the coefficient of variation of the cohesion

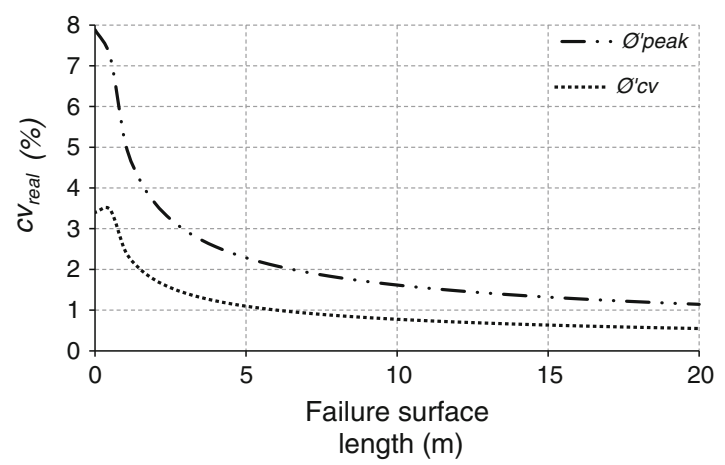

Fig. 15 Influence of the scale of fluctuation in the reduction of the coefficients of variation of the peak and constant volume friction angles

parameter shall be selected as a cautious estimate of the value affecting the occurrence of the limit state". Therefore, when the scale of fluctuation of shear strength is small enough in comparison with the length of a given failure surface such that shear resistance is governed by its average value, it is reasonable to consider it as a cautious estimate of the overall shear strength instead of $5 \%$ fractile proposed in clause 4.2(3) of EN 1990:2002/ A1:2005/AC:2010. That is, in the particular case of geotechnical structures involving materials with similar geomechanical properties to this granite residual soil from Porto, the characteristic value of shear strength can be considered equal to its mean value, as long as local failures are not a matter of concern.

\section{Conclusions}

The granite residual soil from Porto characterized in this paper presents an important lithological heterogeneity, which is very common in these geomaterials and, in this particular case, easily perceived to the naked eye. The coefficients of variation obtained for both physical and mechanical properties are in accordance with the benchmarks presented in the literature for sedimentary soils, specifically for sands, which represent the main granulometric fraction of residual soils from granite. However, the set of values related to effective cohesion are really scattered, with a coefficient of variation that is very close to the maximum upper limit proposed in the literature for clays. Therefore, it might be more accurate and prudent to use an exponential distribution instead of a lognormal law to model the variability of the effective cohesion of a residual soil, mainly because it allows this parameter to assume null values.

Moreover, as the constant volume shear strength depends mostly on pure friction and its coefficient of variation is slightly lower than the one related to the peak shear strength, it could be concluded that the variability of the shear strength is mainly related to the variability of its fabric, which is destroyed when reaching the peak resistance.

Lastly, it is important to note that the values of the horizontal scales of fluctuation of the peak and the constant volume shear strength of the residual soil in question, approximately and respectively 0.4 and $0.5 \mathrm{~m}$, determined according to the simplified procedure suggested by Kulhawy and Phoon (1999), are extremely small when compared with the benchmarks proposed in the literature for other geomechanical parameters of sedimentary soils (see Table 2). Consequently, the fluctuations around the average shear strength are very persistent along short distances which means that, when failure surfaces are long in comparison with the value of the scale of fluctuation, the shear strength of the ground is controlled by its average value, that is, even if the distribution of the shear strength along the failure surface is highly scattered, redistribution of shear stresses can take place and so compensate the lack of shear strength of the most fragile areas. However, as geotechnical properties of residual soils depend on many factors, their statistics may differ significantly from site to site which means that theses scales of fluctuation might not apply to every single granitic soil. Therefore, further investigations should be carried out in the future in order to complement the main conclusions presented in this paper regarding this issue. 
Acknowledgments The authors would like to acknowledge the Geotechnical Laboratory of the Engineering Faculty of the University of Porto (LABGEO-FEUP), in the person of Professor Viana da Fonseca, for providing all the required resources to carry out the experimental tests. Grateful acknowledgements extend to Geologist Lígia Santos for carrying out the geological cartography of the soil analysed in this paper.

Open Access This article is distributed under the terms of the Creative Commons Attribution License which permits any use, distribution, and reproduction in any medium, provided the original author(s) and the source are credited.

\section{References}

ASTM D3080-04. Standard test method for direct shear test of soils under consolidated drained conditions. ASTM International

Baecher G, Christian J (2003) Reliability and statistics in geotechnical engineering. John Wiley \& Sons Ltd., Chichester, England

Bolton M (1986) The strength and dilatancy of sands. Géotechnique 36(1):65-78

Curto J, Pinto J (2009) The coefficient of variation asymptotic distribution in the case of non-iid random variables. J Appl Stat 36(1):21-32

Duncan J (2000) Factors of safety and reliability in geotechnical engineering. $\mathrm{J}$ Geotech and Geoenvironmental Eng 126(4):307-316
EN 1990:2002/A1:2005/AC:2010. Eurocode 0: Basis of structural design. CEN

EN 1997-1:2004/AC:2009. Eurocode 7: Geotechnical designpart 1 -general rules. CEN

Forrest W, Orr T (2010) Reliability of shallow foundations designed to Eurocode 7. Georisk 4(4):186-207

Google Maps (https://www.google.com/maps). Accessed on 2014-04-22

Kulhawy F, Phoon K-K (1999) Characterization of geotechnical variability. Can Geotech J 36(4):612-624

Pinheiro Branco L (2011) Aplicação de conceitos de fiabilidade a solos residuais. MSc thesis, Faculty of Engineering, University of Porto, Portugal (in Portuguese)

Shahin M, Cheung E (2011) Stochastic design charts for bearing capacity of strip footings. Geomech Eng 3(2):153-167

Silva Cardoso A, Matos Fernandes M (2001) Characteristic values of ground parameters and probability of failure in design according to Eurocode 7. Géotechnique 51(6):519-531

Vanmarcke E (1977) Probabilistic modeling of soil profiles. J Geotech Eng Division, ASCE 103(GT11):1227-1246

Viana da Fonseca A, Matos Fernandes M, Silva Cardoso A (1997) Interpretation of a footing load test on a saprolitic soil from granite. Géotechnique 47(3):633-651

Viana da Fonseca A, Rios Silva S, Cruz N (2010) Geotechnical characterization by in situ and lab tests to the back-analysis of a supported excavation in metro do porto. Geotech Geol Eng 28(3):251-264

Weber M, Leemis L, Kincaid R (2006) Minimum KolmogorovSmirnov test statistic parameter estimates. J Stat Comput Simul 76(3):195-206 